\title{
A Novel Sizing Approach for Synchronous Reluctance Machines
}

\author{
Mukhammed Murataliyev, Michele Degano, Member, IEEE, \\ Michael Galea, Senior Member IEEE
}

\begin{abstract}
This paper presents a simple analytical model for the sizing of Synchronous Reluctance (SynRel) machines. The accuracy of the method is achieved by modelling a simple rotor geometry that presents all the characteristics of a real machine. The analytical equations proposed are able to guarantee accurate and fast results during the preliminary design of the machine.

A generalized sizing approach, based on the saliency ratio, is presented in detail. The method is flexible and can be adapted for any SynRel machine. The accuracy of the proposed model is validated, for a range of operating conditions, comparing the results with both finite element simulations and experimental measurement carried out from an existing four poles SynRel 15kW prototype.
\end{abstract}

Index Terms- Synchronous Reluctance Machines, Analytical modelling, Saliency ratio, Sizing.

\section{INTRODUCTION}

$\mathrm{T}$ HE generalized torque relation for common, cylindrical machines can be derived from the magnetic field energy in the machines' air-gap. This depends on the machine volume and is expressed as in [1]. Various adaptations of this sizing technique have been discussed in literature [2], [4]. However, the most common approach is traditionally based around the relationship between the volume and the two main constraints of any machine, namely the magnetic limit and the thermal limit [4], [5].

When used as a preliminary sizing scheme, e.g. for classical analytical sizing tools, then it is well-known that for most common machines this approach can yield excellent preliminary design results [2] [6]. Part of this accuracy comes from the fact that most preliminary sizing operations do not include the machine's saliency ratio at the preliminary design stage. Therefore, for machine topologies where saliency is not so significant, the above approach is quite accurate.

However, when the approach is applied to machines where saliency does play a significant and dominant role, more accurate design methods, such as finite element (FE) analysis, are required [7].

This defeats the whole purpose of a preliminary sizing tool and automatically 'forces' the machine designer towards timeconsuming FE iterations right from the start of the design process. However, if an analytical method that is able to

Manuscript received July 25, 2019; revised November 4, 2019, December 20, 2019 and January 4, 2020; accepted February 6, 2020. This work was supported in part by the Natural Science Foundation of China via the project with code 51850410515.

M. Murataliyev. M. Degano and M. Galea are with Key Laboratory of More Electric Aircraft Technology of Zhejiang Province and consider the saliency ratio at all the design stages is used, then the time required for the initial sizing of the machine can be significantly reduced.

A case in point for the above is the Synchronous Reluctance (SynRel) machine, where the rotor geometry has an important effect on the machine's saliency ratio. Therefore, for SynRel machines, the latter is a critical parameter that needs to be included in any analytical sizing method.

Thus, an analytical sizing approach for SynRel machines that is able to consider the saliency ratio is proposed in this paper. The methodology is applied to SynRel machines with Axially Laminated Anisotropic (ALA) rotor types [8] and to SynRel machines with Transversely Laminated Anisotropic (TLA) rotors [9]. In this paper, the proposed method is shown to result in very good accuracy, while also comprising an inherent flexible nature that allows for appropriate fine-tuning of the method itself. The approach relies on accurate estimations of the direct and quadrature inductance values, also known as the saliency ratio.

The proposed method was successfully validated by a sets of FEA simulations as well as by experimental results, performed on a SynRel machine rated at $15 \mathrm{~kW}$.

\section{ANALYTICAL DERIVATION}

The analytical method described in [8], [10] uses the $d-q$ frame parameters to model an ALA SynRel machine. In these works, the emphasis was on the importance of considering the saliency ratio while adapting the well-known electromagnetic reluctance torque relation in a $d-q$ frame for machine design [6].

The torque equation is given in (1), where $p$ represents the number of pole pairs, $L_{d}$ and $L_{q}$ are the direct and quadrature inductances, respectively; and $I_{d}, I_{q}$ are the direct and quadrature currents flowing in the stator windings.

$$
T_{e m}=\frac{3}{2} p\left(L_{d}-L_{q}\right) i_{d} i_{q}
$$

In (1), the main electromagnetic variables are the direct and quadrature axis inductances. In a reluctance motor within a $d-q$ - reference frame, the $d$-axis is the path of least reluctance and the $q-$ axis is the path of greater reluctance; reflecting into unequal inductances, dependent on the rotor position. Hence, when $L_{d} \neq L_{q}$ an "alignment" torque, alternatively known as the reluctance torque, is present.

\footnotetext{
University of Nottingham Ningbo Campus (UNNC), (email: mukhammed.murataliyev@nottingham.ac.uk michele.degano@nottingham.ac.uk, michael.galea@nottingham.ac.uk)

M. Degano and M. Galea are also with PEMC Group, University of Nottingham, Nottingham, UK.
} 
For such cases, the magnetic conductivity along the rotor surface is not equal. Therefore, the resulting air-gap flux densities can be defined as shown in (2) and (3), where $B_{d}$ and $B_{q}$ are the flux densities along the $d$ and $q$ axis, respectively; $g_{d}(x)$ and $g_{q}(x)$ are the air gap functions and $F_{d}(x)$ and $F_{q}(x)$ are the magneto motive forces (MMF) produced by the stator, which are position dependent $(x)$ :

$$
\begin{aligned}
& B_{d}(x)=\frac{\mu_{0} F_{d}(x)}{g_{d}(x)} \\
& B_{q}(x)=\frac{\mu_{0} F_{q}(x)}{g_{q}(x)}
\end{aligned}
$$

If $B_{1}$ represents the fundamental component of the air-gap flux density for a uniform air-gap machine (no saliency) and $B_{l d}, B_{l q}$ are set to be the fundamental components of $B_{d}$ and $B_{q}$. Their ratios represent the magnetizing inductances $L_{d m} / L_{m}$ and $L_{q m} / L_{m}$ as shown in (4) and (5), where $K_{d m}, K_{q m}$ are the magnetizing coefficients, $L_{d m}, L_{q m}$ are the direct and quadrature magnetizing inductances and $L_{m}$ is the magnetizing inductance of a solid cylindrical rotor.

$$
\begin{gathered}
K_{d m}=\frac{L_{d m}}{L_{m}}=\frac{B_{1 d}}{B_{1}} \\
K_{q m}=\frac{L_{q m}}{L_{m}}=\frac{B_{1 q}}{B_{1}}
\end{gathered}
$$

Consequently, the saliency ratio $\xi$ can then be defined as shown in (6), where $L_{l}$ represents the leakage inductance:

$$
\xi=\frac{L_{d}}{L_{q}}=\frac{L_{d m}+L_{l}}{L_{q m}+L_{l}}=\frac{L_{m} K_{d m}+L_{l}}{L_{m} K_{q m}+L_{l}}
$$

Considering that the values of peak MMF $\left(n_{s} I_{s}\right), n_{s}$ - number of turns, $I_{s}$ - peak phase current, should be the same for both the $d$ and $q$ axis excitations, then it can be said that the values of $K_{d m}$ and $K_{q m}$ are entirely geometrical parameters and can therefore be analytically derived.

On the other hand, the magnetizing inductance $L_{m}(6)$ has a nonlinear dependence on the machine MMF, due to the magnetic saturation of steel. However, $L_{m}$ can be determined for the linear region using an analytical inductance model to form an initial design, which can be further improved, later on using FE modelling. [11]

\section{A. $D-Q$ parameters approximation:}

The main inductance of a single phase of the stator winding $L_{s p}$ can be calculated using the peak values of a single-phase flux linkage $\lambda_{s}$ and the stator phase current $I_{s}[1,11] . L_{m}$ is determined by multiplying $L_{s p}$ by a factor of $\mathrm{m} / 2$, where $m$ is the number of phases, due to the mutual inductance between phases. For 3-phase machines, the magnetizing inductance is calculated as shown in (7), where $D_{r o}$ is the rotor diameter, $L$ is the stack length, $q$ is the number of slots per pole per phase, $g$ is the air gap length, $\mu_{0}$ is the relative permeability of air. $K_{w l}$ and $K_{s}$ are winding factor and saturation coefficient, respectively.

In (7), the parameters $D_{r o}$ and $L$ are the variables of interest as these determine the size of the machine. These will be derived later based on the torque requirements (1) and (6).

$$
L_{m}=\frac{3}{2} L_{s p}=\frac{3}{2} \frac{\lambda_{s}}{I_{s}}=3 \mu_{0} D_{r o} L \frac{\left(q K_{w 1} n_{s}\right)^{2}}{g K_{c}\left(1+K_{s}\right)}
$$

The values of the excitation currents in the $d-q$ frame then need to be derived to determine the torque through (1). A common way to evaluate the values of $I_{d}$ and $I_{q}$ is to consider them as parts of $d-q$ frame MMF values $F_{d}$ and $F_{q}$, which are closely related to the air gap flux density, that can be calculated using (2), (3).

The general equation for the fundamental component of the direct axis air gap flux density can then be derived from (4) (6). This is shown in (8).

$$
B_{1 d}=\frac{B_{1}}{\sqrt{1+\left(\frac{K_{q m}}{K_{d m}}\right)^{2} \xi}}
$$

Consequently, the stator MMF in the $d-q$ frame can then be derived as given by (9) and (10):

$$
\begin{gathered}
n_{s} I_{d}=\frac{B_{1 d} \pi g\left(1+K_{s}\right)}{3 \sqrt{2} \mu_{0} q K_{w 1} K_{d m}} \\
n_{s} I_{q}=n_{s} I_{d m} \sqrt{\xi}
\end{gathered}
$$

Considering (1) and (4) - (10), it is clear that the magnetizing coefficients $K_{d m}$ and $K_{q m}$ are solely dependent upon the machine topology. Therefore, for salient pole machines the values change, whereas for a non-salient machine, the value is equal for both direct and quadrature axes.

Utilizing equations (4) - (10), all the $d$ - $q$ reference frame parameters for any machine topology can be derived, and subsequently used to estimate the torque through (1).

\section{B. Linear sizing:}

As can be observed in (1), torque is directly proportional to the difference between $L_{d}$ and $L_{q}$. Thus, minimizing $L_{q}$ results in an increasing torque. This suggests that $L_{q m}$ is mostly a leakage inductance. Therefore, it can be said that the fundamental component of the field is mainly found in the daxis component.

Therefore, considering $L_{d}>>L_{q}$ as a first approximation, then the saliency ratio can be expressed by (11).

$$
\xi=\frac{L_{d}}{L_{q}}=\frac{L_{d m}+L_{l}}{L_{q m}+L_{l}}=\frac{L_{m} K_{d m}+L_{m} K_{q m}}{2 L_{m} K_{q m}}
$$

Therefore, the magnetizing coefficients ratio can be described by (12).

$$
2 \xi-1=\frac{K_{d m}}{K_{q m}}
$$

If the machine presents only a reluctance component, in the case of a SynRel motor, then the rotor outer diameter $\left(D_{r o}\right)$ can be written based on (1) and (7) - (12) as (13):

$$
D_{r o}=\sqrt{\frac{T_{e m} \gamma \mu_{0} q K_{d m} \sqrt{\xi}}{B_{1 d}^{2} \pi g\left(1+K_{s}\right) \sqrt{1+\left(\frac{1}{2 \xi-1}\right)^{2} \xi}}}
$$

From (13), the importance of saliency for reluctance machines and the main machine sizing ratio, represented by the aspect ratio, can be observed. The aspect ratio is proportional to the machine stack length and inversely proportional to the outer rotor diameter [1]: 


$$
\gamma=\frac{L}{D_{\text {ro }}}
$$

Based on (13) it is clear that the main geometrical input parameters of the rotor sizing equation are the air-gap $g$ and the aspect ratio $\gamma$. The saliency ratio $\xi$ is one of the parameters required to determine $D_{\text {ro }}$. As $\xi$ is directly dependent on the rotor topology, then it needs to be properly defined. The typical saliency ratio value is $\xi \leq 10$ for TLA and $\xi>10$ for ALA [12].

From all the above, it can be concluded that the main parameters that define the saliency ratio are the magnetizing coefficients given by (6). Since, in (7), $L_{m}$ has been determined in the linear region of a magnetic circuit of the machine and referring to (6) and (11), it can be concluded that the unsaturated saliency ratio is a geometrical parameter.

Based on (4) and (5), $K_{d m}$ and $K_{q m}$ can be estimated using an air gap flux density distribution of the $d$ and $q$ axis rotor excitation. One of the analytical techniques that can be used to estimate the air gap flux density distribution for (2) and (3) is the air gap function method [13].

The air gap function method is the most suitable when uneven magnetic conductivity throughout the periphery of the air gap needs to be considered $B_{d} \neq B_{q}$. This method is less complex than other approaches that determine the flux density distribution, yet still manages to reflect uneven magnetic conductivity, for both salient pole as well as TLA and ALA rotor topologies [14].

\section{AIR GAP FUNCTION APPROACH FOR SALIENCY DERIVATION}

The air-gap function is an analytical method that is widely used to calculate air-gap flux density, due to its consideration of the rotor and stator slotting effects. In [8], an approach for the computation of the field distribution was presented for the ALA topology of a SynRel, however the stator slotting effects were neglected. In [14], a method for the accurate prediction of the no-load flux distribution of field-excited flux-switching motor (FE-FS) was proposed, including an air gap function in the magnetic circuit. In this case, the rotor topology was that of a salient pole configuration with DC stator excitation. Another variant of a salient pole rotor topology was studied in [13], however AC stator excitation was used and the FEA torque estimation was analyzed in comparison to the values obtained using an air gap magnetic circuit. In summary, the air-gap function approach is used to reflect a stator and rotor slotting effect on the air gap flux density distribution.

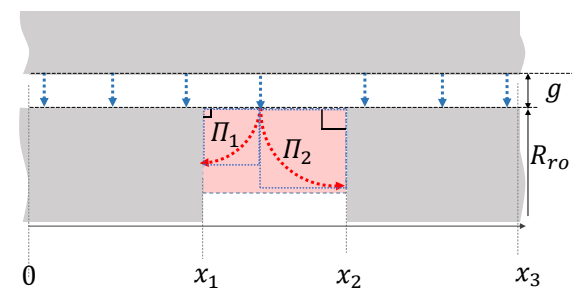

Fig. 1 Rotor slotting, magnetic flux using infinite slot approach.
The slotting effect can be analyzed and understood using the air gap function method through the generic geometry shown in Fig. 1.

As can be observed, the machine flux encounters a nonuniform permeability, due to the presence of the slot openings, or if considering a TLA, the saturated iron.

The air-gap function for a salient pole rotor can be derived according to the infinite slotting assumption, where the idealized magnetic flux $\Pi_{1}$ and $\Pi_{2}$ are assumed to be equal to quarter circumference of a circle [14], [13].

The length of the flux lines perpendicular to the rotor can be easily estimated using cylindrical coordinates and the rotor outer radius $R_{r o}$ as presented in equation (15), which are position $(x)$ dependent. $(x)$ is an angle expressed in polar coordinates, which will be used in further derivations.

$$
\begin{gathered}
\Pi_{1}=-\pi R_{\text {ro }} \sin \frac{x}{2} \\
\Pi_{2}=-\pi R_{\text {ro }} \sin \left(\frac{x_{1}}{2}-\frac{x}{2}\right)
\end{gathered}
$$

Therefore, the total flux path's length can be estimated by using the parallel paths derivation, as described by (16).

$$
\Pi_{1} \| \Pi_{2}=\frac{\pi R_{\text {ro }} \sin \left(\frac{x}{2}\right) \sin \left(\frac{x_{1}-x}{2}-\frac{x}{2}\right)}{\sin \left(\frac{x}{2}\right)+\sin \left(\frac{x_{1}-x}{2}-\frac{x}{2}\right)}
$$

As can be observed in Fig. 1, the total air gap has increased as a result of the additional slot introduced from $x_{1}$ to $x_{2}$. The total length of the air flux path for the considered period can therefore be defined as shown in (17).

$$
g(x)=\left\{\begin{array}{rc}
g, & 0<x<x_{1} \\
g+\Pi_{1} \| \Pi_{2}, & x_{1}<x<x_{2} \\
g, & x_{2}<x<x_{3}
\end{array}\right.
$$

The following method can be used to estimate the air flux paths considering salient pole rotor slotting, as well as the insulation barriers of TLA and ALA SynRel rotor topologies.

\section{A. Anisotropic rotor geometry considerations:}

The SynRel ALA and TLA topologies have a very complex barrier structure comprising a high number of geometrical parameters that must be considered [15]. A typical example is illustrated in Fig. 2. However, this paper is mainly focused on the effects of the saliency and magnetizing ratio on the preliminary sizing of the machine. Thus, to simplify the geometry complexity, only four parameters are considered namely the number of barriers, the insulation ratio, angle span of each barrier and angular thickness of each barrier with respect to rotor surface. This assumption of neglecting the other geometrical parameters is valid because the aim is to derive the magnetic circuit for idealized magnetic condition, i.e. when the iron is magnetically unsaturated hence, the iron reluctance can be assumed to be zero. Therefore, the reluctance is present only due to the air gap and interior rotor barrier insulations, conventionally known to be air.

Considering the generic geometrical parameters, as shown in Fig. 2, then the comprehensive parametrization of flux barriers can be achieved $[7,13,14,15]$. The flux barriers are drawn according to a conformal mapping theory and the Joukowski 
air-flow potential formulation. The expression for each barrier line is defined by the coefficient $C_{k}$, which is described in (18).

$$
C_{k}=\sin \left(p \alpha_{k}\right) \frac{\left(\frac{r}{a}\right)^{2 p}-1}{\left(\frac{r}{a}\right)^{p}}
$$

The calculated $C_{k}$ is then used to derive the cylindrical coordinate of each point on the borderline of the barrier. This is done through (19).

$$
r\left(\alpha_{k}, C_{k}\right)=a \sqrt[p]{C_{k}+\frac{\sqrt{C_{k}^{2}+4 \sin ^{2} p x}}{2 \sin (p x)}} 0 \leq x \leq \frac{\pi}{p}
$$

All the above shows that having set the geometrical parameters as for example shown in Fig. 2, then all the parameters of interest can be derived from (18) and (19). Thus, $\Delta \alpha_{k}$, i.e. the per unit value of barrier span angle with respect to $q$-axis, $\beta_{k}$, i.e. the angular thickness of each barrier opening and $h c_{k}$ i.e. a per unit value that represents the insulation barrier thickness can all be found. The total insulation ratio $k_{\text {air }}$ can be derived as an average value of $h c_{k}$ as described in (20).

$$
k_{\text {air }}=\frac{\sum_{k} h c_{k}}{k}
$$

Using the air gap function approach, the same function with a phase lag of $45^{\circ}$ for 4 -pole can be derived for the $d$-axis and $q$-axis rotor excitation.

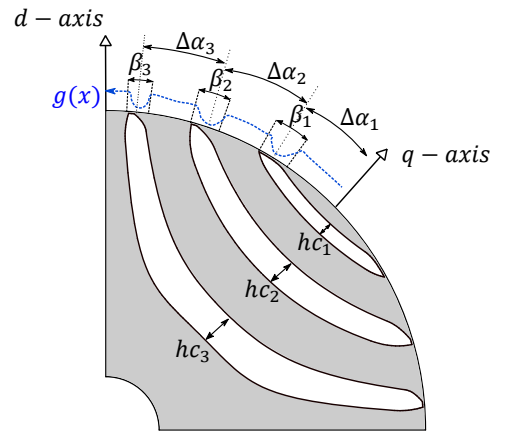

Fig. 2. Quarter of geometry for anisotropic type rotor (3 - barriers in this case), 4-pole configuration. Based on $\Delta \alpha_{k}$ (per unit value of $\alpha$ ) and $h c_{k}$ (per unit value of barrier thickness).

However, the $q$-axis air gap function should include an extra reluctance component due to insulation barriers, in this case air. Therefore, it increases with the air thickness of a flux path.

\section{1) Air Gap Function for D-axis excitation:}

The thickness of the air-gap for $d$-axis excitation should only consider the barrier slotting effect as presented in Fig. 2, by using (15) and (16). The total rotor air gap function for the $n-$ barriers rotor for the $d$-axis excitation can be expressed as a position $(x)$ dependent function, which is given in (21).

$$
g_{r d}(x)=\left\{\begin{aligned}
& 0, 0<x<x_{1} \\
& \Pi_{1} \| \Pi_{2}, x_{1}<x<x_{1}+\beta_{1} \\
& 0, x_{1}+\beta_{1}<x<x_{2} \\
& \ldots \\
& \Pi_{1} \| \Pi_{2}, x_{n}<x<x_{n}+\beta_{n} \\
& 0, x_{n}+\beta_{n}<x<x_{n+1}
\end{aligned}\right.
$$

\section{2) Air Gap Function for Q-axis excitation:}

For the $q$-axis excitation, the magnetic circuit should be built considering $h c_{k}$. Therefore, an extra air thickness in this case needs to be considered, such as shown in Fig. 3.

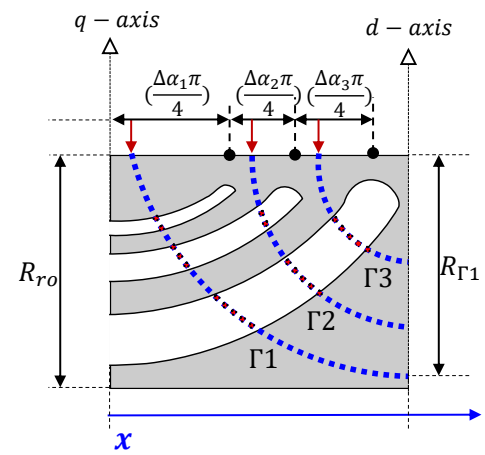

Fig. 3. Idealized flux paths for $q$-axis excitation (tangentially flattened rotor), flux path through air barriers is highlighted with red.

The flux paths can be estimated in a similar method to (15) considering quarter-circular flux paths through a half-pole rotor segment. Therefore, the $k_{\text {air }}$ ratio can be used to derive the air barriers thickness with respect to flux paths $\Gamma 1-\Gamma 3$ depending on position $(x)$ as shown in Fig. 3. Using cylindrical coordinates of the flux paths' starting points, the radius of the flux line $\Gamma_{n}$ can be derived as (22) and the air path thickness as (23).

$$
\begin{gathered}
R_{\Gamma \mathrm{n}}=\frac{R_{r o} \Delta \alpha_{n} \pi}{4} \\
\Gamma_{n} * k_{\text {air }}=\left[\frac{R_{\text {ro }} \Delta \alpha_{n} \pi}{4}\right] \frac{\pi}{2} * k_{\text {air }} \\
k_{\text {air }} \cdot \Gamma_{1}, \quad 0<x<x_{1} \\
k_{\text {air }} \cdot \Gamma_{2}, \quad \begin{aligned}
\Pi_{1} \| \Pi_{2}+\Gamma_{1}, & x_{1}<x<x_{1}+\beta_{1}<x<x_{2} \\
\Pi_{1} \| \Pi_{2}+k_{\text {air }} \cdot \Gamma_{\mathrm{n}}, & x_{n}<x<\beta_{n} \\
k_{\text {air }} \cdot \Gamma_{\mathrm{n}}, & \beta_{n}<x<x_{n+1}
\end{aligned}
\end{gathered}
$$

Based on the geometrical parameters from Fig. 2 and Fig. 3, the magnetic circuit can be expressed for the $q$-axis. The rotor air gap function for $n$-barriers rotor for $q$-axis excitation can be expressed as a position $(x)$ dependent relationship, as shown in (24).

\section{B. Stator slotting considerations}

When considering the stator slotting effect, the magnetic flux paths can be approximated in a similar manner as (15) using an infinite slot assumption. However, the tooth tip can be accounted using the slotting effect with external flux paths, highlighted with red in Fig. 4.

Thus for a geometry such as shown in Fig. 4, the angle of an external flux path span can be derived by the relationship described in (25), where, $w_{s p}$ is the tooth tip width and $h_{s 2}$ is the height of the wedge. 


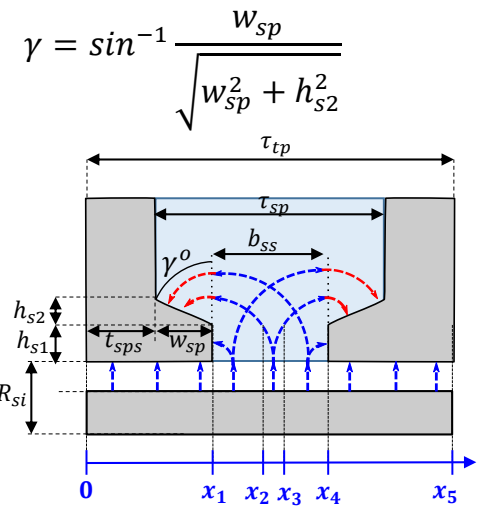

Fig. 4. Stator slotting, magnetic flux using infinite slot approach, where slotted region is highlighted in blue.

From (25), a relationship that describes the flux paths in proximity to the slot opening can be derived and this is shown in (26), where $\Pi_{s 11}$ and $\Pi_{s 22}$ are the flux paths extensions due to the tooth tip and $\Pi_{s l}$ and $\Pi_{s 2}$ are the quarter-circular flux paths.

$$
\begin{aligned}
& \Pi_{s 1}=\pi R_{s i} \sin \left(\frac{x}{2}\right) \\
& \Pi_{s 2}=\pi R_{s i} \sin \left(\frac{b_{s s}}{2}-\frac{x}{2}\right) \\
& \Pi_{s 11}=\left[R_{s i} \sin \left(\frac{x}{2}\right)-h_{s 1}\right] \gamma \\
& \Pi_{s 22}=\left[R_{s i} \sin \left(\frac{x}{2}\right)-h_{s 1}\right] \gamma \\
& g_{s}(x)=\left\{\begin{aligned}
0, & 0<x<x_{1} \\
\Pi_{s 1} \|\left(\Pi_{s 2}+\Pi_{s 22}\right), & x_{1}<x<x_{2} \\
\Pi_{s 1} \| \Pi_{s 2}, & x_{2}<x<x_{3} \\
\left(\Pi_{s 1}+\Pi_{s 11}\right) \| \Pi_{s 2}, & x_{3}<x<x_{4} \\
0, & x_{4}<x<x_{5}
\end{aligned}\right.
\end{aligned}
$$

Therefore, based on (25), (26) and Fig. 4, a magnetic circuit can be derived that emulates the stator slotting. In turn, a periodic, position $(x)$ dependent air gap function considering stator slotting only, can be derived and this is given in (27).

\section{Magnetizing coefficients and saliency ratio:}

The general periodic expression of an air gap function considering both rotor and stator slotting can be derived based on (21), (24), and (27). Hence, the total air path thickness for a salient pole rotor considering stator slotting can be derived as given in (28) and (29), where $g$ is the air gap thickness between rotor and stator.

$$
\begin{aligned}
& g_{d}(x)=g_{r d}(x)+g_{s}(x)+g \\
& g_{q}(x)=g_{r q}(x)+g_{s}(x)+g
\end{aligned}
$$

From (4) and (5), further expansion can be done with the aid of a Fourier series. The magnitudes of the fundamentals $d-q$ excited flux densities can then be described by (30) and (31):

$$
\begin{aligned}
& B_{1 d}=\frac{4 \mu_{0} F_{1 d}}{\tau} \int_{0}^{\tau / 2} \frac{1}{g_{d}(x)} \cos ^{2} \frac{\pi x}{\tau} d x \\
& B_{1 q}=\frac{4 \mu_{0} F_{1 q}}{\tau / 2} \int_{0}^{\tau / 2} \frac{1}{g_{q}(x)} \sin ^{2} \frac{\pi x}{\tau} d x
\end{aligned}
$$

The magnetizing coefficients of (5) and (6) can then be simplified. The simplified coefficients $K_{d m}$ and $K_{q m}$ can be described by (32) and (33), where $g(x)$ is an air gap function for a non-salient rotor with a constant air gap, such as $g(x)=g$ and $\tau$ is the pole pitch.

The parameters $g_{d}(x)$ and $g_{q}(x)$ are the air gap functions with respect to direct and quadrature axes excitations of the rotor derived in (28), (29).

$$
\begin{gathered}
K_{d m}=\frac{4}{\tau} \int_{0}^{\tau / 2} \frac{g(x)}{g_{d}(x)} \cos ^{2}\left(\frac{\pi x}{\tau}\right) d x \\
K_{q m}=\frac{4}{\tau} \int_{0}^{\tau / 2} \frac{g(x)}{g_{q}(x)} \cos ^{2}\left(\frac{\pi x}{\tau}\right) d x \\
\text { Table I. Slot opening parameters }
\end{gathered}
$$

\begin{tabular}{ccc}
\hline \hline Symbol & Parameter & Quantity \\
\hline \hline$b_{s s}$ & Slot opening & $3 \mathrm{~mm}$ \\
$h_{s 1}$ & Slot opening height & $1 \mathrm{~mm}$ \\
$h_{s 2}$ & Wedge height & $1 \mathrm{~mm}$ \\
\hline \hline \multicolumn{2}{c}{ Table II. Rotor geometry considerations }
\end{tabular}

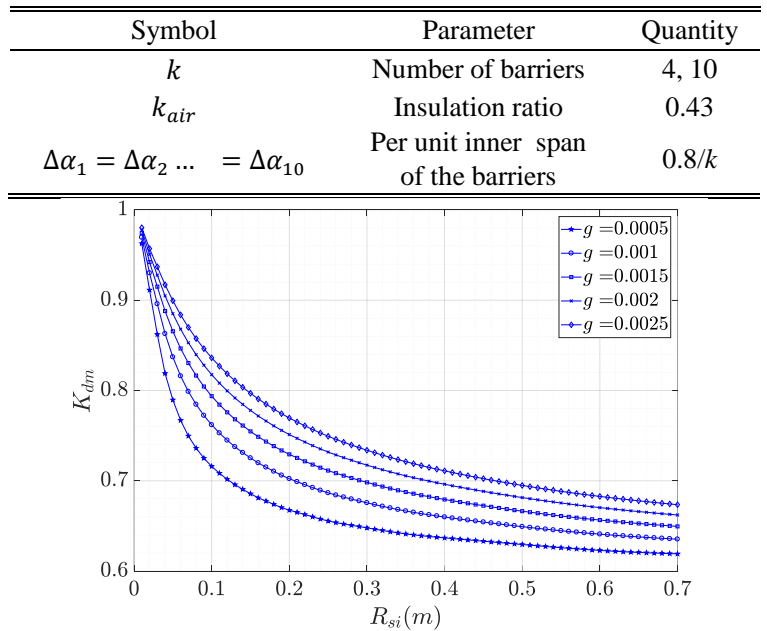

Fig. 5. Magnetizing coefficient $K_{d m}$ as a function of geometrical parameters: $g$ is an air gap length, and $R_{s i}$ is the stator inner radius, both expressed in $m$.

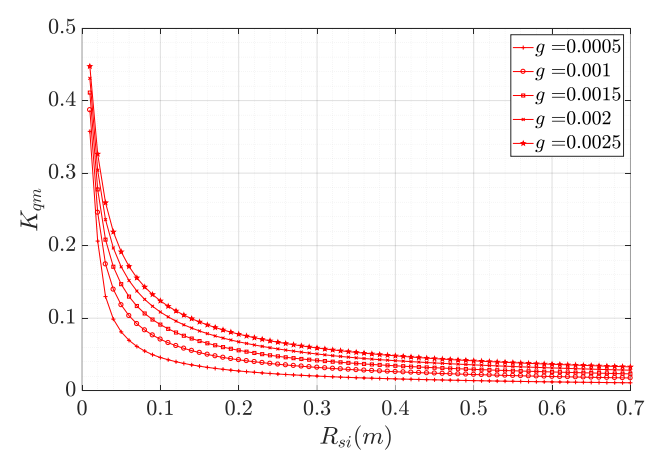

Fig. 6. Magnetizing coefficient $K_{q m}$ as a function of geometrica parameters: $g$ is an air gap length, and $R_{s i}$ is the stator inner radius, both expressed in $m$.

Using equations (32) and (33), then various values of rotor diameters and air gap lengths can be investigated. This study is done on a machine geometry that is defined by the values given 
in Table I and Table II. Fig. 5 and Fig. 6 show the estimated values of $K_{d m}$ and $K_{q m}$ when both stator and rotor slotting are considered.

As can be observed from Fig. 5 and Fig. 6, for small values of the ratio $R_{s i} / g$, the behaviour of $K_{d m}$ differs from $K_{q m}$. The latter increases significantly with the decrease of $R_{s i} / g$, compared to $g$. In general, the air gap value is limited by mechanical constrains, therefore using (13), the rotor radius has to be sufficiently big relative to the air gap in order to achieve designed values of saliency and torque.

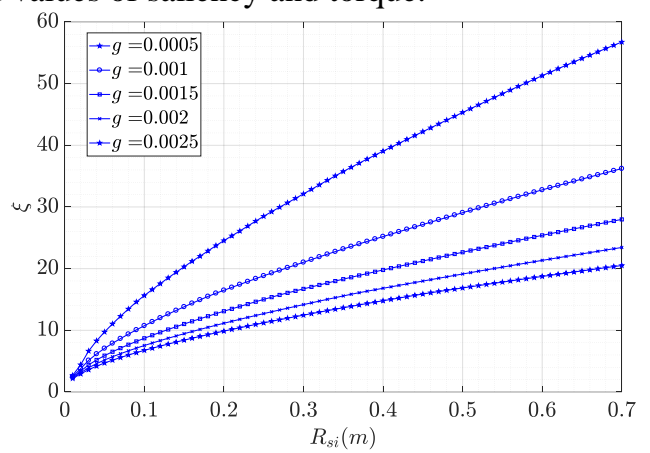

Fig. 7. Unsaturated saliency ratio and neglected leakage $\xi$ for various $R_{s} / g$ combination

$K_{d m} / K_{q m}$ represents an unsaturated value for magnetizing ratio and in the case when the machine has a minimum of leakage flux the ratio can be approximated to a saliency ratio.

The results based on Fig. 5 and Fig. 6 are plotted in Fig. 7 according to the rotor dimensions from Table II. It can be concluded that the saliency ratio has a dependency on $R_{s i} / g$. Therefore, it needs to be properly predefined according to the torque requirements (13). However, air gap function approach can be used to estimate $K_{d m}$ and $K_{q m}$, hence the saliency ratio.

\section{SALIENCY RATIO CONSIDERING SATURATION}

As it was concluded in the previous section, the unsaturated saliency ratio is a pure geometrical parameter. However, $d-q$ axes inductances are not constant for different values of stator current due to the nonlinear magnetic property of the stator and rotor iron, hence the saliency ratio will change as well.

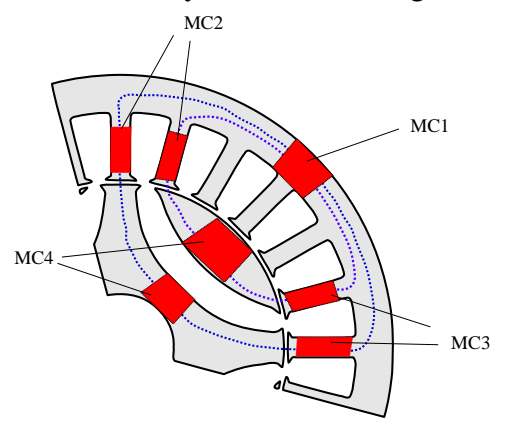

Fig. 8. Magnetic circuit with the highlighted segments subject to saturation for d-axis.

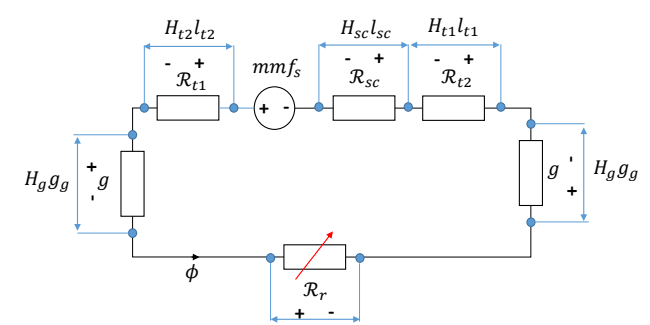

Fig. 9. Simplified magnetic circuit of one pole.

\section{A. Simplified magnetic circuit:}

A common way to express magnetic saturation is to derive a saturation coefficient. Such a saturation coefficient can be defined as a ratio of the fundamental of total $\mathrm{mmfs}$ of the magnetic circuit and the fundamental of the air gap mmf [10] [17]. Fig. 8

Using the flux paths schematic of Fig. 8, the magnetic circuit can be derived as shown in Fig. 9. The four main reluctances are $R_{t 2}$ and $R_{t l}$ which are tooth iron reluctances and $R_{s c}$ and $R_{r}$ which are the stator and rotor core iron reluctances respectively. $R_{g}$ is the air gap reluctance. The stator iron reluctances can be derived based on the stator geometry [10]. The rotor reluctance should consider the current excitation angle, in a similar manner as it was discussed in Fig. 3. However, the iron reluctance is now considered. As the rotor's saturation level will fully depend on the current vector angle $\alpha^{e}$, then $R_{r}$ is a function of $\alpha^{e}$.

$$
\alpha^{e}=\tan ^{-1} \frac{I_{q}}{I_{d}}
$$

Using equations (22) and (23) the flux paths of rotor iron and rotor air insulation can be derived as functions of $\alpha^{e}$; as shown in (35) and (36), where $R_{r o}$ and $R_{s h}$ are the rotor and shaft radiuses

$$
\begin{gathered}
\Gamma_{\text {iron }}=\frac{\left(R_{\text {ro }}-R_{s h}\right) \pi}{2}\left(1-k_{\text {air }}\right) \cos \left(\alpha^{e}\right) \\
\Gamma_{\text {air }}=\frac{\left(R_{\text {ro }}-R_{s h}\right) \pi}{2} k_{\text {air }} \sin \left(\alpha^{e}\right)
\end{gathered}
$$

Hence, the rotor equivalent reluctance will be derived as given by (37), where $A_{r}$ is the average cross sectional area of a single rotor pole:

$$
\mathcal{R}_{r}=\frac{\Gamma_{\text {iron }}}{\mu_{r} A_{r}}+\frac{\Gamma_{\text {air }}}{\mu_{0} A_{r}}
$$

Since the insulation barriers have a high reluctance, the flux that is flowing through the circuit, shown in Fig. 9, will be reduced. This can be approximated as:

$$
\phi=\frac{m m f_{s}}{\mathcal{R}_{s c}+2 \mathcal{R}_{g}+\mathcal{R}_{t 1}+\mathcal{R}_{t 2}+\mathcal{R}_{r a}+\mathcal{R}_{r i}}
$$

The flux equation can be modified depending on the current vector angle $\alpha^{e}$ such as described in (39):

$$
\begin{aligned}
& \phi_{\alpha}{ }^{e}=0 \sim \frac{m m f_{s}}{\mathcal{R}_{s c}+2 \mathcal{R}_{g}+\mathcal{R}_{t 1}+\mathcal{R}_{t 2}+\mathcal{R}_{r i}} \\
& \phi_{0<\alpha^{e}<90} \sim \frac{m m f_{s}}{\mathcal{R}_{s c}+2 \mathcal{R}_{g}+\mathcal{R}_{t 1}+\mathcal{R}_{t 2}+\mathcal{R}_{r a}+\mathcal{R}_{r i}}
\end{aligned}
$$

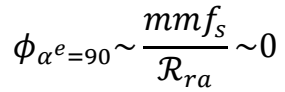


When $\alpha^{e}=0$, the flux will not pass through the insulation barriers. If $0<\alpha^{e}<90$, the circuit will present an extra reluctance component, since flux will now pass through the insulation barriers. Hence, the flux will decrease, as it is inversely proportional to $\Gamma_{\text {air }}(36)$. When $\alpha^{e}=90$, it can be said that $\phi=0$, due to high reluctance of the barriers.

$$
\phi \propto \mathcal{R}_{r}\left(\alpha^{e}, k_{\text {air }}\right)
$$

Based on the circuit presented the Fig. 9, the total mmf can be derived by the relationship (41), where $l_{t 1}, l_{t 2}$ and $A_{t 1}, A_{t 2}$ are teeth flux path lengths and average tooth cross sectional areas; $l_{c s}$ is the flux path length through the stator core and $A_{c}$ is the average cross sectional area of the stator core, $g$ - air gap length and $A_{g}$ is the average cross sectional area at the air gap. $R_{r}$ can be derived as presented in equations (35) - (37):

$$
m m f_{s}=\phi\left(\frac{l_{t 1}}{A_{t 1} \mu_{r}}+\frac{l_{t 2}}{A_{t 2} \mu_{r}}+\frac{l_{c s}}{A_{c} \mu_{r}}+\frac{2 g}{A_{g} \mu_{0}}+\mathcal{R}_{r}\right)
$$

Based on all the above the saturation levels will depend on the insulation ratio and current vector angle.

\section{$B$. The principle of saturation modelling:}

The saturation model is built, based on the air gap flux density as it is discussed in [10]. However, it has to be modified considering the magnetizing coefficients $K_{d m}$ and $K_{q m}$ (31), (32), which quantify the magnetic conductivity of $d$ and $q$ axis. Therefore, the air gap flux density for a given MMF will vary according to the current vector angle $\alpha^{e}$ as described in (42), where $B_{g}$ is fundamental of the air gap flux density of a SynRel machine and based on $B_{1}$ which is the fundamental component of the air-gap flux density for a uniform air-gap machine (no saliency).

$$
B_{g}=B_{1}\left(K_{d m} \cos \left(\alpha^{e}\right)+K_{q m} \sin \left(\alpha^{e}\right)\right)
$$

In order to model the effect of saturation the B-H property of the iron material should be used - to determine required $\mathrm{mmf}$ for calculated flux density levels. Fig. 10 presents a simple flow chart to determine the saturation levels for a designed machine.

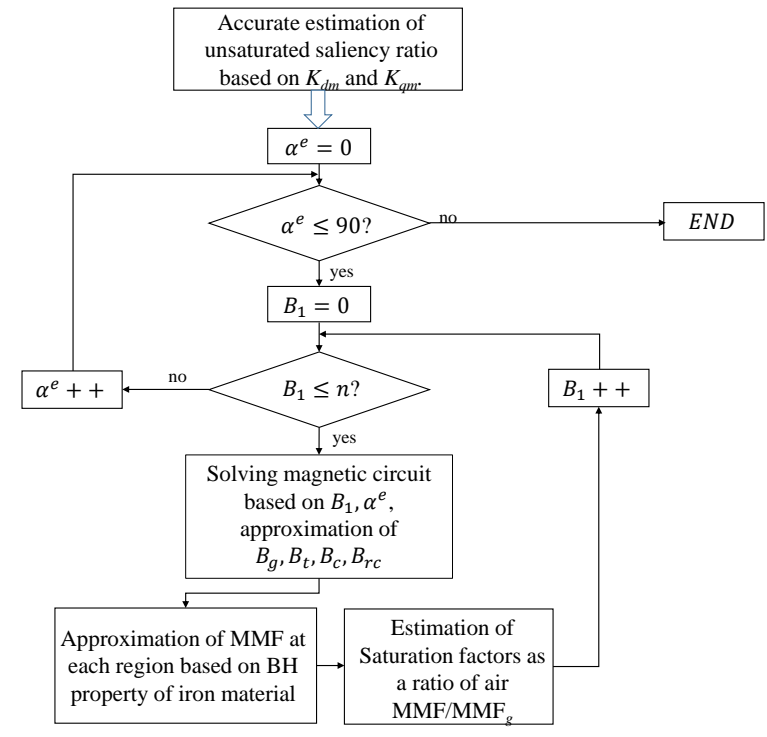

Fig. 10. Flow Chart of saturation modelling.
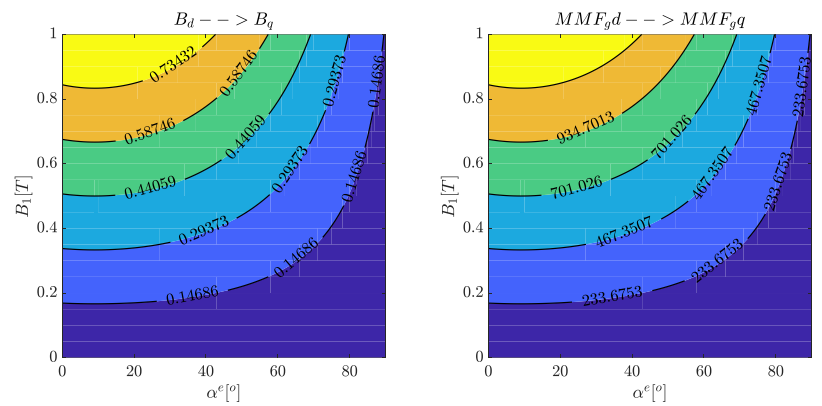

Fig. 11. SynRel air gap flux density and MMF levels.
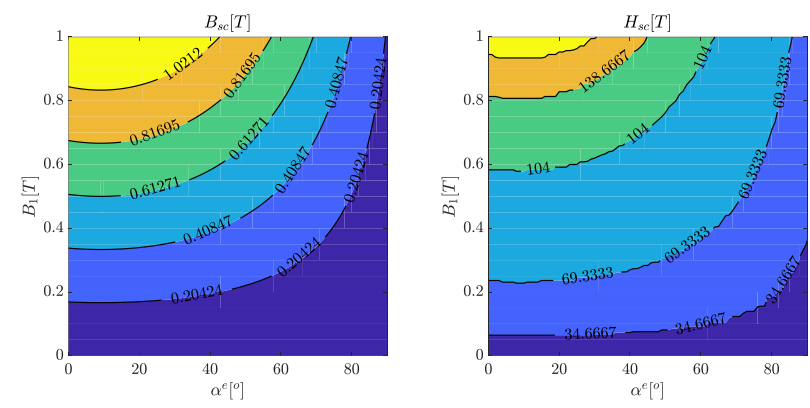

Fig. 12. Stator back iron flux density and magnetic field strength levels.

Fig. 11 presents air gap flux density and air gap mmf for a typical $K_{d m}=0.86, K_{q m}=0.14$. Using these flux density values for stator and rotor using approach described in Fig. 10 can be derived. I.e. Fig. 12, Fig. 13 present a flux density and magnetic field strength levels for iron M530-65A (reported in Appendix), for $g=0.5 \mathrm{~mm}, A_{g}=0.00174 \mathrm{~m}^{2}, A_{t}=0.00124 \mathrm{~m}^{2}, A_{c}=0.005 \mathrm{~m}^{2}$.
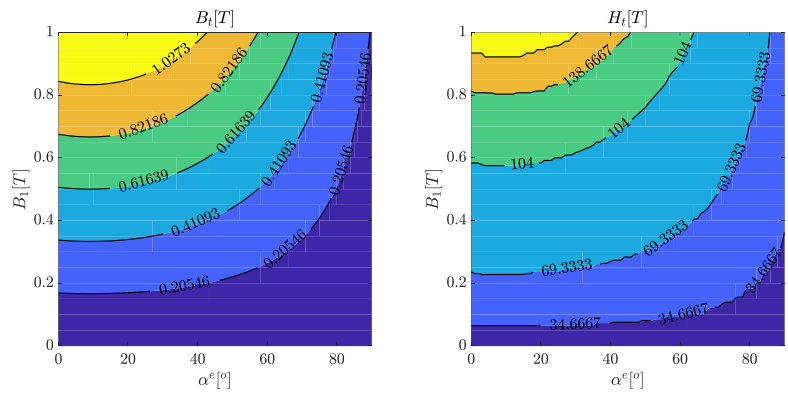

Fig. 13. Stator tooth flux density and magnetic field strength levels.

In a similar way, the flux density and $\mathrm{mmf}$ can be derived for any region of a magnetic circuit Fig. 8.

\section{Saturation factors:}

The saturation coefficient is defined as a ratio of the total mmf fundamental of the magnetic circuit and fundamental of the air gap mmf [10], [17].

Air gap mmfs can be derived using magnetizing coefficients (31) and (32) and the fundamental air gap flux density $B_{l}$ as:

$$
\begin{aligned}
2 F_{g d} & =\frac{2 g B_{1} K_{d m}}{\mu_{0}} \\
2 F_{g q} & =\frac{2 g B_{1} K_{q m}}{\mu_{0}}
\end{aligned}
$$

Saturation coefficients $K_{s d}$ and $K_{s q}$ can be derived considering the magnetic circuits Fig. 9, equations (9) and (41) for $d$ and $q$ axises as (43) - (46): 


$$
\begin{gathered}
K_{s d}=\left(\frac{m m f_{s}}{2 F_{g d}}\right) \\
\sim \frac{n_{s} I_{s} 3 \sqrt{2} \mu_{0} q K_{w 1}}{\pi g 2 B_{1} K_{d m}}\left(1-k_{\text {air }}\right) \cos \left(\alpha^{e}\right) \\
K_{s q}=\left(\frac{m m f_{s}}{2 F_{g q}}\right) \\
\sim \frac{n_{s} I_{s} 3 \sqrt{2} \mu_{0} q K_{w 1}}{\pi g 2 B_{1} K_{q m}}\left(1-k_{\text {air }}\right) \sin \left(\alpha^{e}\right)
\end{gathered}
$$

The magnetic circuits of $d-q$ circuits will saturate based on the current vector angle $\alpha^{e}$ and insulation ratio $k_{\text {air }}$. As it is described in Fig. 10 the B-H curve of iron material can be used to determine the magnetic field strength based on the estimated flux densities at each considered segment Fig. 8. The mmf of each iron segment can be identified using magnetic field strength and the path length, Fig. 10. Hence using (41) - (46), the saturated circuit can be modelled.

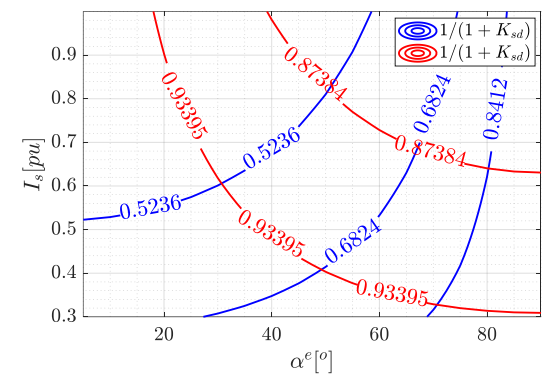

Fig. 14. Inverse saturation coefficients as functions of $I_{s}$ and $\alpha^{e}$. $K_{d m}=0.8, K_{q m}=0.03$.

The accuracy of the approximation of saturation factors will depend on the number of magnetic circuit segments considered Fig. $8[17,18,19]$.

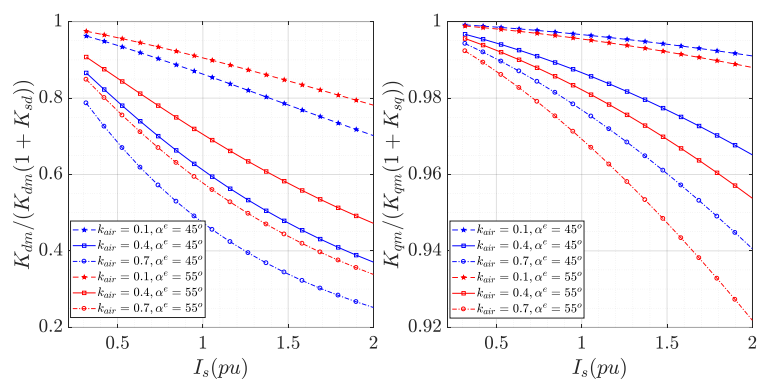

Fig. 15. $d-q$ inductances as functions of $I_{s}$ and $\alpha^{e}$, and $k_{\text {air. }}$.

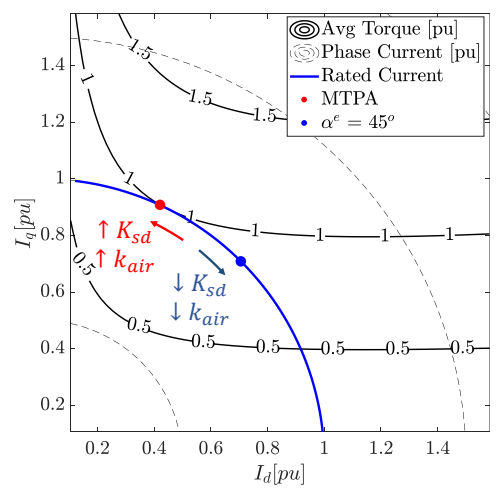

Fig. 16. SynRel pu Torque profiles on Id-lq plane.
Using equations (7), (11), (32), (33), (45), (46) the saliency ratio considering saturation coefficients can be derived as (47):

$$
\xi=\frac{K_{d m}\left(1+K_{s d}\right)+K_{q m}\left(1+K_{s q}\right)}{2 K_{q m}\left(1+K_{s q}\right)}
$$

While $d-q$ axis inductances can be derived using (6), (7), (11), (45), (46) as:

$$
\begin{gathered}
L_{d}=\frac{L_{m} K_{d m}}{\left(1+K_{s d}\right)}+\frac{L_{m} K_{q m}}{\left(1+K_{s q}\right)} \\
L_{q}=\frac{2 L_{m} K_{q m}}{\left(1+K_{s q}\right)}
\end{gathered}
$$

Fig. 14 presents an inverse of the saturation coefficients as a functions of peak phase current $I_{s}$ and current vector angle. Referring to equations (47) and (48) it can be stated that the inverse function of saturation coefficients $K_{s d}$ and $K_{s q}$ represent per unit values of $L_{d}$ and $L_{q}$.

Fig. 15 presents a per unit values of inductances for $k_{a i r}=0.1$; $0.4 ; 0.7, R_{r o}=84.5 \mathrm{~mm}, g=0.5 \mathrm{~mm}$ based on equations (47) (48). It can be observed that higher insulation ratio $k_{\text {air }}$ results in lower value of $L_{q}$ due to reduction of $K_{q m}$. However, higher $k_{\text {air }}$ will increase the $d$-axis saturation coefficient $K_{s d}$ due to reduction of the iron magnetic paths. Therefore, according to equations (44) - (48) d-axis inductance tend to decrease at lower current compared to q-axis inductance due to the rotor iron saturation. As can be observed on Fig. 15, for a typical SynRel machine when $k_{a i r} \sim 0.4$ the $d$-axis inductance is about three times the decrease of q-axis [15]. When the iron saturation occurs, the operating current vectors is achieved at higher angle $\alpha^{e}$. Fig. 16 presents a typical SynRel Torque profiles on $I d-I q$ plane that can be derived based on (46), (47) and (1). As can be observed, when the machine's $d$-axis is saturated i.e at high $k_{\text {air }}$, the operating current vector (MTPA- maximum torque per ampere) is achieved at higher angle $\alpha^{e},\left(I_{q}>I_{d}\right)$. And if the $d$ axis is unsaturated the operating current vector is at $\alpha^{e}=45^{\circ}$.

In summary, the saturation level can be evaluated by checking if the MTPA for a rated torque value will match the typical rated current vector angle $\alpha^{e} \sim 60^{\circ}$, using the torque equation (1) and the updated values of $L_{d}, L_{q}(47)-(48)$. If the value of $\alpha^{e}>60^{\circ}, k_{\text {air }}$ can be reduced. If the value of $\alpha^{e} \sim 45^{\circ} k_{\text {air }}$ can be increased as it is presented in Fig. 16.

\section{Preliminary model Validation by means of FE:}

To validate all the above, FE models are built and then used to evaluate geometries resulting from the analytical equations (6), (12), (13), (32), (33).

The initial parameters considered for the designs evaluation are summarized in Table III with stator and rotor dimensions based on Table I and Table II to evaluate the model's range (relative to machine dimensions) the approach was tested for a wide range of SynRel machines. To ensure fair comparisons, all the machines were set with the same current density. This was achieved by modifying the stator slot geometry [2]. The results of this analysis are illustrated in Fig. 17.

Table III. Details of FEA validation

\begin{tabular}{ccc}
\hline \hline Symbol & Parameter & Quantity \\
\hline$p$ & Number of poles pairs & 2
\end{tabular}




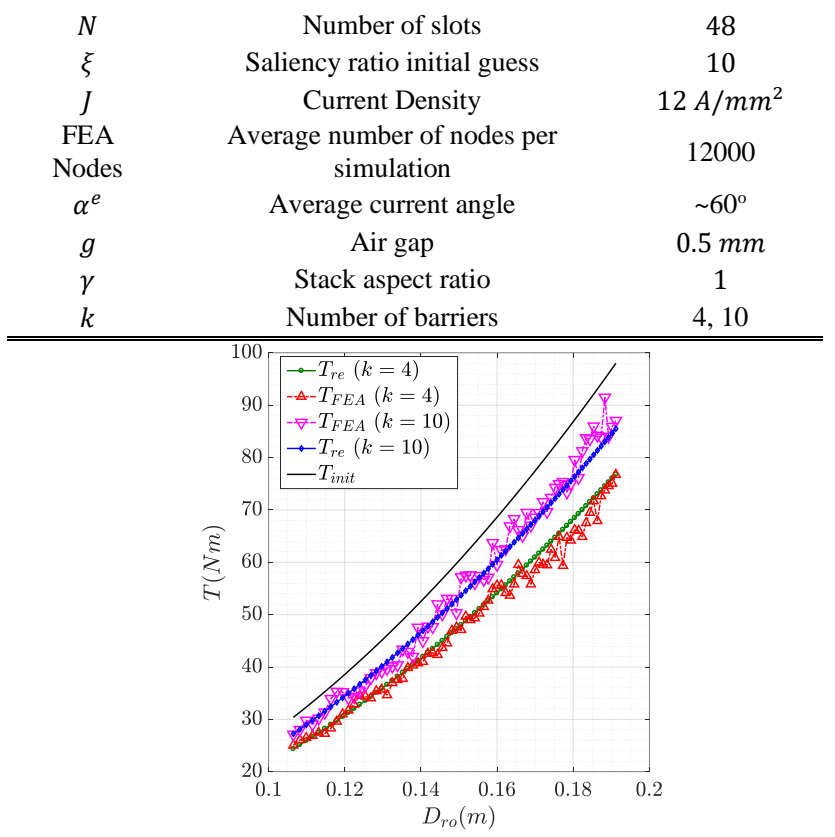

Fig. 17. Average torque comparison, for a range of different rotor diameter: $T_{r e}$ - refined torque values using air gap function.

The black continuous line in Fig. 17 represents an initial torque $T_{\text {init }}$ estimation according to the size of the machine. This is achieved using equation (16) and a predefined saliency. Considering the air gap function, a better approximation of torque, can then be obtained $T_{r e}$. The air gap function (32), (33) is thus used to fine-tune and update $K_{d m}, K_{q m}$ and $\xi$, as according to (13). This is highlighted with blue and green lines for $k$ equal to 4 and 10 , respectively.

To achieve the results shown in Fig. 17, 140 FE simulations for two different rotor topologies were required. Fig. 17 presents a very good correlation of a refined data with respect to the FEA simulated values $T_{F E A}$ for a range of $0.1065 m$ to $0.1912 \mathrm{~m}$ rotor diameters. . The average errors for $T_{r e}$ compared with $T_{F E A}$ are $\delta_{k=4}=1.51 \%$ and $\delta_{k=10}=1.92 \%$. The total time for 140 FE simulations $t \sim 169$ minutes and Analytical simulations $t \sim 1.08$ minutes.

It can be concluded, that a 10-barrier geometry has higher torque capability for the same rotor size, when compared to 4barrier geometry.

This was successfully reflected using refined values for $K_{d m}$, $K_{q m}$ and $\xi$. All the above proves that the analytical sizing approach, based on (13), (32) and (33) is actually very accurate and matches significantly well with the FE results.

\section{SIZING METHOD}

Having confirmed the adequateness of the proposed analytical models, then the models can be used to develop a design tool for SynRel machines. A visualization of this method, presented here as a flow chart is given in Fig. 18. The sizing process begins with a set of initial data and assignment of the key parameters. These are used in calculations of geometric, magnetic, and electric parameters in conjunction with the analytical model of the machine. In this step, the predesign output parameters are the desired rated output power, the current density as well as number of poles and slots.

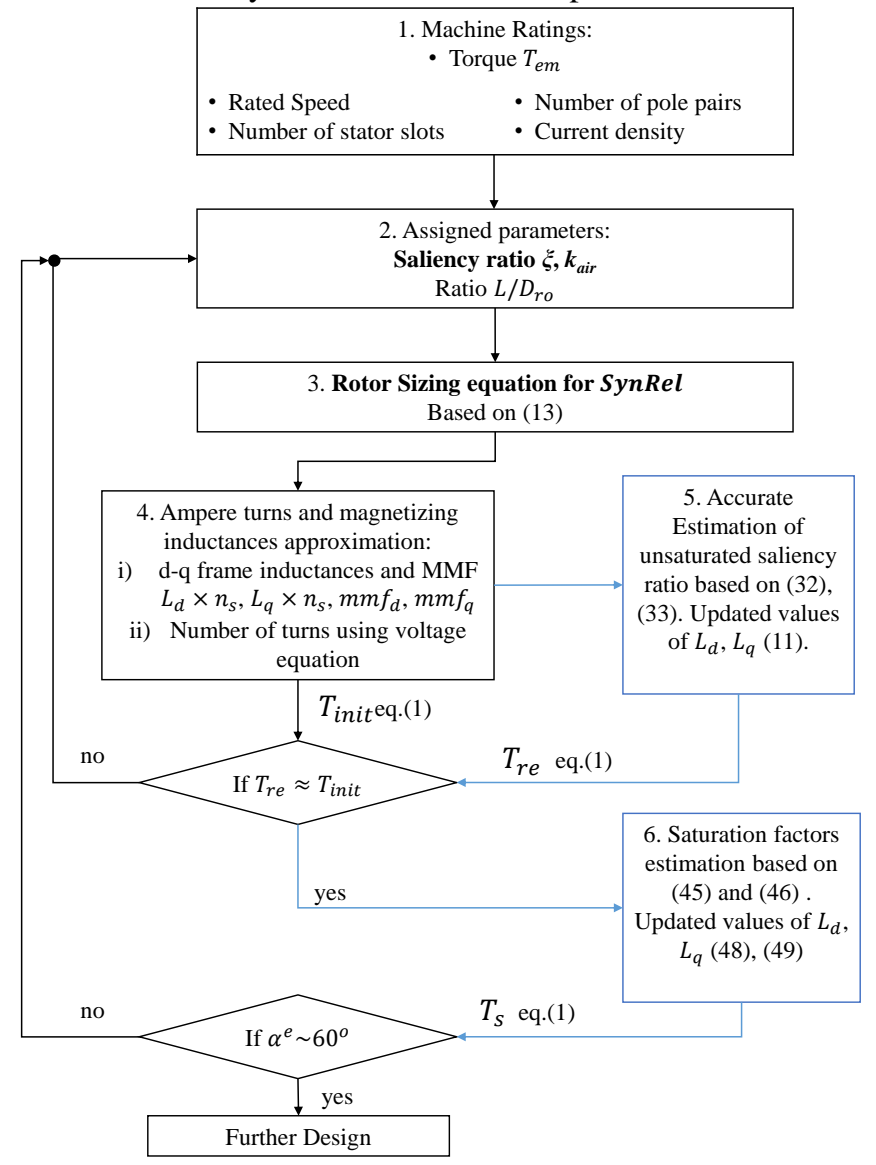

Fig. 18. Flow chart of the Analytical Sizing Method

1) The assigned parameters are the parameters that can be varied and fine-tuned. Few assumptions can be made as discussed in Sec. II, referring to equation for saliency ratio estimation (12), which later on can be adjusted according to (32) - (33).

2) The main sizing step is the rotor diameter $D_{r o}$ estimation (13).

3) Using equations (6) - (11) and the predefined saliency ratio (12), the main $d-q$ parameters can be estimated. At this point the number of turns for (7) - (10) and (12) - (13) is not considered. Equation (1) can be used for the initial torque estimation $T_{\text {init }}$, using predefined value of saliency.

4) The geometry of the rotor's barriers can be estimated using any preferable method [15], however the main input parameters to estimate the machine saliency should be according to Table II. Considering the rotor geometry, using the method described in Sec. III, (32) and (33) can be used for the estimation of the main rotor parameters $K_{d m}$, $K_{q m}$ and $\xi$. The refined saliency ratio $\xi$ is used to estimate an accurate torque value (1) $T_{r e}$. Later, $T_{r e}$ can be compared with $T_{\text {init }}$. Hence, geometry should be adjusted so that $T_{r e} \approx$ $T_{\text {init. }}$

5) Saturation coefficients $K_{s d}$ and $K_{s q}$ can be derived as it is described in Sec. IV. Hence updated values $\xi$ and $L_{d}$ and $L_{q}$ 
can be used to draw the Torque current profiles as it is shown on Fig. 16. To check the saturation level a quick MTPA study can be done using the method described in Sec. IV.

\section{CASE Study}

In order to validate the proposed methodology, an existing four poles 48 slots SynRel prototype is considered as a case study. Details of the final design are presented in Table IV, with a summary of the key motor parameters. Magnetizing coefficients $K_{d m}$ and $K_{q m}$ were derived using (32), (33).

\section{A. Inductance validation with respect to FEA results}

As a first step to validate the proposed models, the inductances of the machine are considered.

Table IV. Final parameters of tested 15kW SynRel

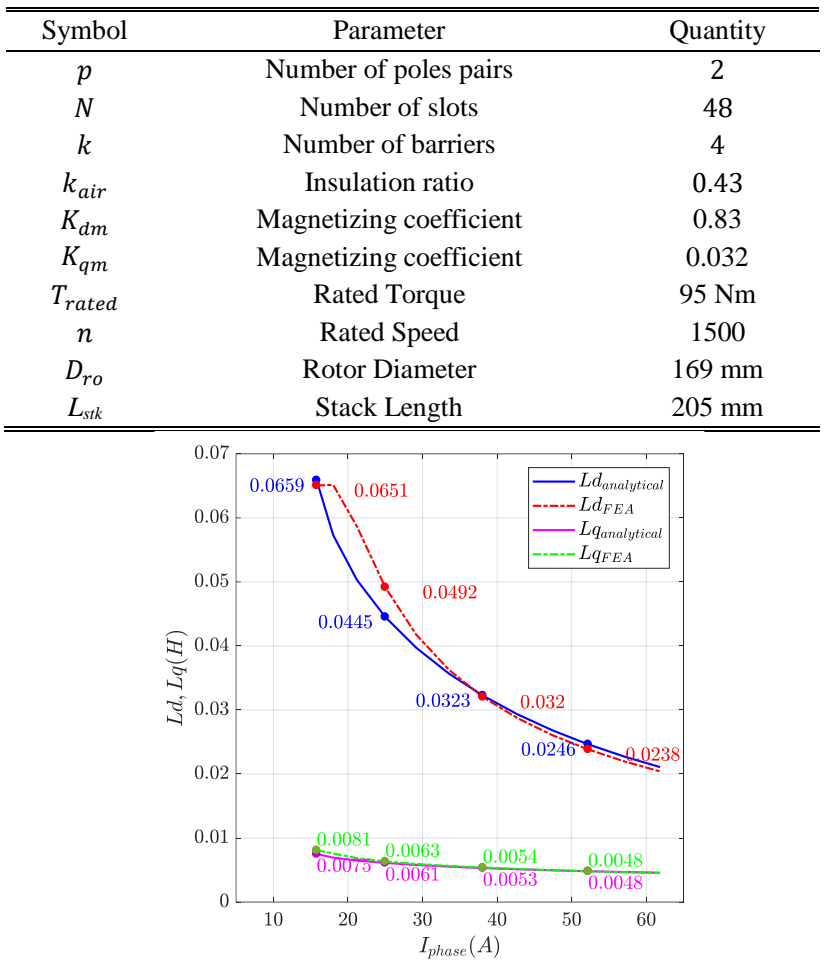

Fig. 19. Variation of inductance with the change of $I_{d}$. With 4 highlighted data points.

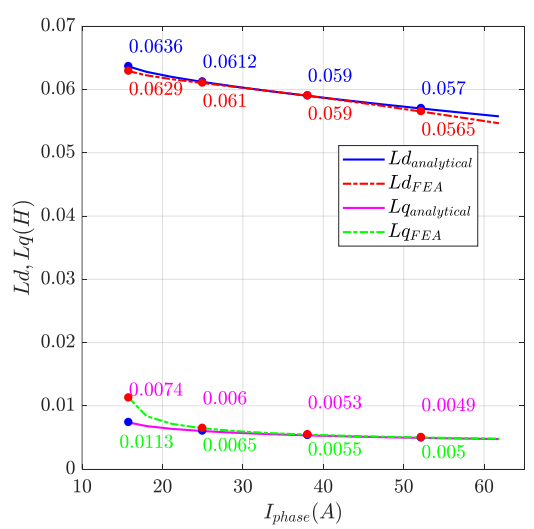

Fig. 20. Variation of inductance with the change of Iq. With 4 highlighted data points.
The first test was carried out at fixed $I_{q}=15 \mathrm{~A}$, for various values of $I_{d}$. The results of this test are shown in Fig. 19. This test is also very important as for SynRel machines, the d-axis excitation effects heavily the saturation in the machine.

As can be observed at low current values, there is a significant difference between the FEA and Analytical results. As mentioned above, this is due to dependence on saturation coefficients (44), (45); however, at higher values of current the error is reduced. At $I_{m}=38.08 \mathrm{~A}$ the error in $L_{d}$ is $\delta_{L d}=4.35 \%$, and in $L_{q}$ is $\delta_{L q}=2.23 \%$.

The next step was a validation exercise for the machine having a fixed value of $I_{d}=15 \mathrm{~A}$, for various values of $I_{q}$. In this case, it can be said that the saturation coefficient is constant due to low Permeance of the q-axis and thus the inductance values will have a small change, therefore the torque is proportionally to the current. This can all be observed in Fig. 20 where the, analytical values of inductances do change with the change of $I_{q}$, the excellence of the proposed model can also be observed in Fig. 20, where the prediction error is very small for the rated $I_{m}$ of $47.4 A$. In fact, at this rating, the $L_{d}$ error is $\delta_{L d}=1.33 \%$, while the $L_{q}$ error is $\delta_{L q}=1.31 \%$.

\section{$B$. Torque validation with respect to FEA results}

Using the equations (1), (7), (48), (49), torque can be calculated for different $I_{d}$ and $I_{q}$ values for a given geometry Table IV.

The calculation speed comparison of the modelling based on the equations (1), (7), (32), (33), (48), (49) and FEA simulations is shown in Table $\mathrm{V}$.
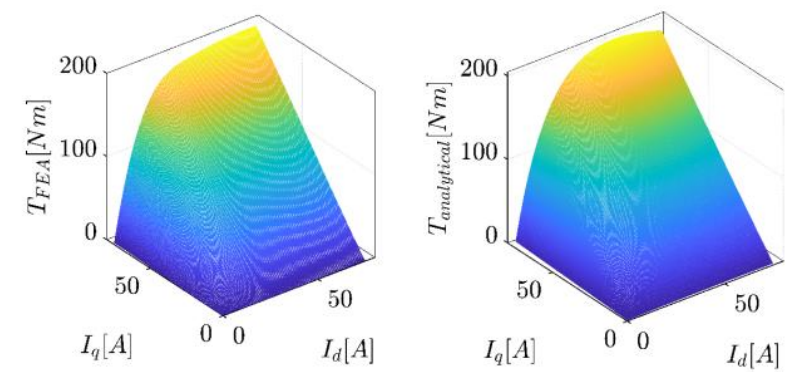

Fig. 21. FEA vs analytical torque current profiles.

Fig. 21 presents FEA simulated and analytically estimated torque vs current profiles. The average error of the Torque is $\delta_{T} \sim 6.53 \%$. As mentioned previously, the accuracy of saturation factors approximation will depend on the number of magnetic circuit segments considered. In order to keep the simplicity of the approach only 4 segments of the one pole magnetic circuit were considered as it was discussed in Sec. IV. However, the methodology of the approach presented can be modified and an accurate modelling tool of SynRel machines can be derived.

Table V. Summary of FEA vs analytical modelling

\begin{tabular}{cccc}
\hline \hline & $\begin{array}{c}\text { Number of } \\
\text { simulations }\end{array}$ & Time & Error \\
\hline FEA & 25 & $720 \mathrm{sec}$ & - \\
Analytical Tool & 5625 & $2.1 \mathrm{sec}$ & $6.53 \%$ \\
\hline \hline
\end{tabular}




\section{Sizing method validation with respect to FEA results}

According to the sizing tool that was derived previously as presented on Fig. 18, the rated saliency ratio should be accurately estimated in order to properly tune the machine geometry to satisfy the required torque.

Table VI. Rated Saliency ratio

\begin{tabular}{ccc}
\hline \hline Symbol & Parameter & Quantity \\
\hline$I_{d}$ & d-axis current & $24.9 \mathrm{~A}$ \\
$I_{q}$ & q-axis current & $40.2 \mathrm{~A}$ \\
$\xi_{\text {analytical }}$ & Analytical value of saliency ratio & 9.08 \\
$\xi_{F E A}$ & Saliency ratio based on FEA & 9.03 \\
$T_{\text {analytical }}$ & simulations & $99.1 \mathrm{Nm}$ \\
$T_{F E A}$ & Torque analytical & $97.4 \mathrm{Nm}$ \\
\hline
\end{tabular}

Using equations (47) saliency ratio can be calculated for a rated current, and torque at rated conditions can be calculated using (1), (48), (49). Table VI presents analytical and FEA values of saliency ratio and Torque at rated current conditions.

Analytical saliency ratio was estimated according to the magnetizing coefficients that were derived, as presented in Table IV. The error in saliency ratio with respect to FEA is $0.6 \%$, while the error in torque is $1.71 \%$. Therefore, it can be concluded that the method can accurately estimate the saliency ratio at rated conditions for the given machine size and geometry. Hence, the algorithm presented in Fig. 18 is able to accurately size SynRel machine according to the torque requirements.

\section{EXPERIMENTAL VALIDATION}

The experimental platform used to validate the proposed analytical sizing method presented is shown in Fig. 22. On the left hand side, the SynRel prototype under test is mounted on the test rig movable base. The motor is self-ventilated through a fan mounted on the rotor shaft. A resolver is also mounted on the non-drive end of the SynRel motor, to provide the speed feedback to the drive.

Under the protection guard a torque meter is installed. The load machine on the left hand side is a $40 \mathrm{~kW}$ induction motor, with a forced ventilation cooling system. The main results in terms of the torque performance are illustrated in Fig. 23, which plots the produced torque on $I_{d}-I_{q}$ plane.

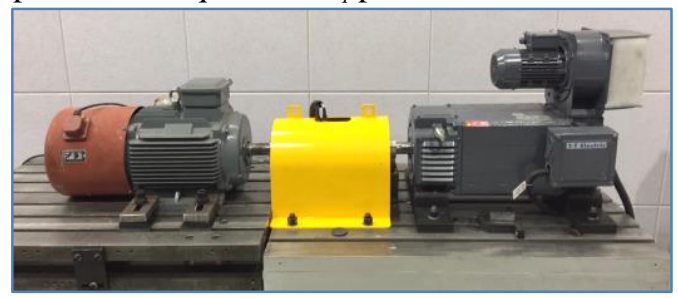

Fig. 22. Test rig: 15kW SynRel motor (left hand side) and 40kW induction machine used as a load (right hand side).

As can be observed in Fig. 23, the model results match very well with the experimental results. The errors over the low to rated current range are very small. Above the rated current value, the error increases. This error can be attributed to the uncertainty of the analytical model when it comes to saturation, as a simple 4 segment magnetic circuit was used in calculation of the saturation factors (35) - (49).

Table VII. Highlighted data points, for different rated current angles.

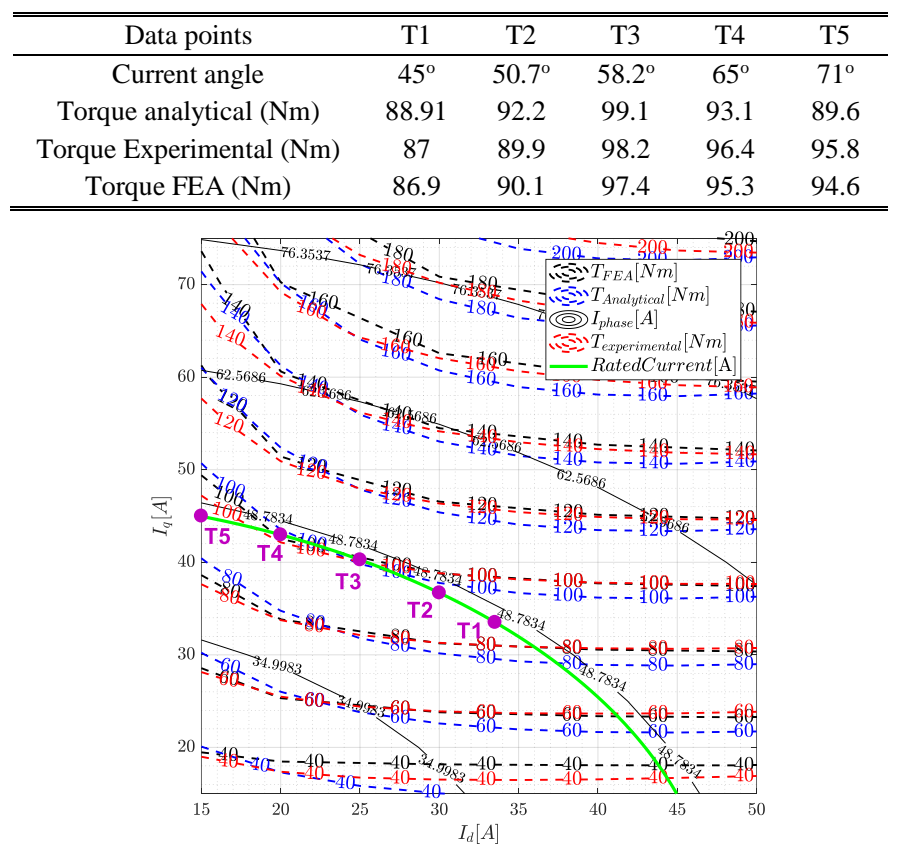

Fig. 23. Comparison of Torque values on Id-lq plane.

Table VII presents a comparison of highlighted torque points on $I_{d}-I_{q}$ plane from Fig. 23 . As can be observed the MTPA current vector angle for the rated current is $\alpha^{e}=58.2^{\circ}$. Analytical approach is able to predict the MTPA current vector angle for the rated current. Hence it can be concluded that the approach derived in Sec. V is able to accurately estimate $\alpha^{e}$ for a rated torque.

\section{CONCLUSION}

This paper has proposed an advanced methodology for the sizing and design of SynRel machines, based on an accurate but fast analytical model. The work demonstrates the accuracy of the sizing method proposed. This has been achieved by considering saliency in preliminary sizing, which later on is fine-tuned using an air gap function approach.

The method algorithm is presented for SynRel machine sizing, suitable for both Axially Laminated and Transverse Laminated rotor topology. It is however perceived that the proposed methodology can also be adopted for simple salient pole rotor structures.

The model was validated using sets of FEA simulations as well as experimental results on a $15 \mathrm{~kW}$ SynRel motor designed and tested. The experimental results are in line with the theoretical prediction: the analytical estimation of the average torque throughout over a wide current range is fast and accurate. At rated current, the error of analytical value is about $2.75 \%$.

It can be concluded that this work is defining a fast and accurate method for the preliminary sizing of Reluctance Machines that can be adopted by the research and industrial community. 


\section{APPENDIX}

Fig. 24. presents the B-H curve property of the M530-65A iron that was used in the examples of Fig. 12 and Fig. 13. Details of the curve are given in Table VIII.

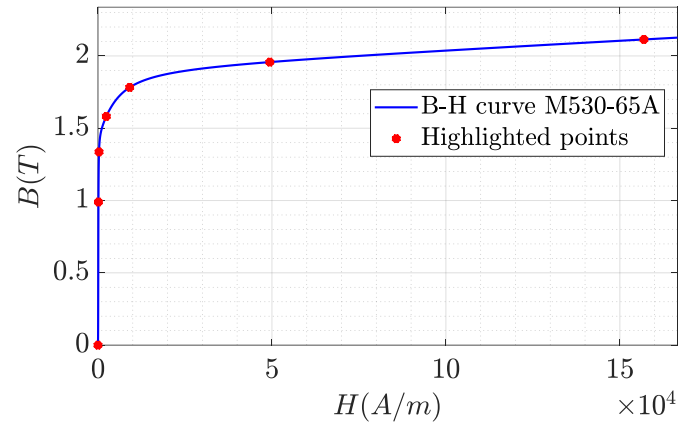

Fig. 24. M530-65A iron B-H curve with highlighted points.

Table VIII. Highlighted B-H curve points M530-65A iron.

\begin{tabular}{|c|c|c|c|c|c|c|c|}
\hline $\mathrm{H}(\mathrm{Amp} / \mathrm{m})$ & 0 & 138.1 & 302 & 2384 & 9134 & 49400 & 156900 \\
\hline $\mathrm{B}(\mathrm{T})$ & 0 & 0.9897 & 1.336 & 1.581 & 1.783 & 1.957 & 2.114 \\
\hline
\end{tabular}

\section{ACKNOWLEDGMENT}

This work was supported in part by the Natural Science Foundation of China via the project with code 51850410515.

\section{REFERENCES}

[10] I. Boldea and S. Nasar, The Induction machines design handbook. 2009.

[11] P. Ponomarev, Y. Alexandrova, I. Petrov, P. Lindh, E. Lomonova, and J. Pyrhonen, "Inductance calculation of tooth-coil permanentmagnet synchronous machines," IEEE Trans. Ind. Electron., vol. 61, no. 11 , pp. 5966-5973, 2014.

[12] S. Taghavi, S. Member, and P. Pillay, "A Core Analysis of the
Synchronous Reluctance Motor for Automotive Applications," vol. 2, no. 2, pp. 961-967, 2014.

[13] G. De Recherche and U. H. Poincaré, "Comparison Between FiniteElement Analysis and Winding Function Theory for Inductances and Torque Calculation of a Synchronous Reluctance Machine," vol. 43, no. 8, pp. 3406-3410, 2007.

[14] B. Gaussens, E. Hoang, O. De La Barrière, J. Saint-Michel, M. Lecrivain, and M. Gabsi, "Analytical approach for air-gap modeling of field-excited flux-switching machine: No-load operation," IEEE Trans. Magn., vol. 48, no. 9, pp. 2505-2517, 2012.

[15] G. Pellegrino, T. M. Jahns, N. Bianchi, W. Soong, and F. Cupertino, The Rediscovery of Synchronous Reluctance and Ferrite Permanent Magnet Motors. Springer, 2016.

[16] N. Bianchi, M. Degano, and E. Fornasiero, "Sensitivity analysis of torque ripple reduction of synchronous reluctance and interior PM motors," IEEE Trans. Ind. Appl., vol. 51, no. 1, pp. 187-195, 2014.

[17] J. Pyrhonen, T. Jokinen, V. Hrabovcova, and H. Niemela, Design of Rotating Electrical Machines. 2008.

[18] B. Stumberger, G. Stumberger, D. Dolinar, A. Hamler, and M. Trlep, "Evaluation of Saturation and Cross-Magnetization Effects in Interior Permanent-Magnet," Ind. Appl. IEEE Trans., vol. 39, no. 5, pp. 12641271, 2003.

[19] K. Shima, K. Ide, M. Takahashi, and S. Member, "Steady-State Magnetic Circuit Analysis of Salient-Pole Synchronous Machines," ENERGY CONVERSION, vol. 18, no. 2, pp. 213-218, 2003.

[20] Z. Zhong, S. Jiang, and G. Zhang, "Magnetic Equivalent Circuit Model of Interior Permanent-Magnet Synchronous Machine Considering Magnetic Saturation," KINTEX Conf. Korea, pp. 1-10, 2015.

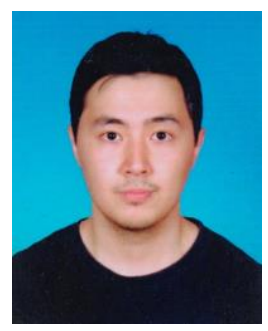

Mukhammed Murataliyev received his M.Sc. degree in electrical engineering from the University of Nottingham, Semenyih, Malaysia in 2016. He is currently pursuing a Ph.D. degree at the University of Nottingham Ningbo China and UK, with a focus on novel synchronous reluctance motor design and optimization methods. His main research interest includes modeling of synchronous reluctance and permanent magnet machines for industrial and aerospace applications.

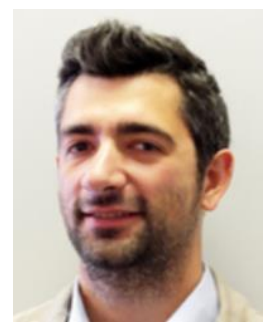

Michele Degano (M'15) received the Laurea degree in electrical engineering from the University of Trieste, Trieste, Italy, in 2011, and the Ph.D. degree in industrial engineering from the University of Padova, Padova, Italy, in 2015. In 2015, he joined the Power Electronics, Machines and Control Group, The University of Nottingham, Nottingham, U.K., where he is currently an Assistant Professor teaching advanced electrical machines design modules. His main research interests include design and optimization of electrical machines for industrial, automotive and aerospace applications, ranging from small to large power. He is currently leading research projects for the development of future hybrid electric aerospace platforms.

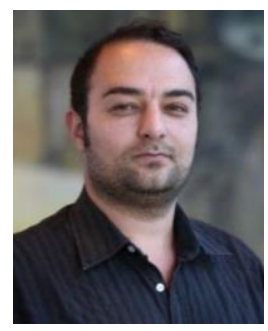

Michael Galea (M'13-SM'18, FRAeS) received his $\mathrm{PhD}$ in electrical machines design from the University of Nottingham, UK, where he has also worked as a Research Fellow. He is currently the Head of School of Aerospace in the University of Nottingham, Ningbo, China, where he is also the Director of Aerospace. He currently lectures in Electrical Drives and in Aerospace Systems Integration and manages a number of diverse projects and programmes related to the more / all electric aircraft, electrified propulsion and associated fields. His main research interests are design, analysis and thermal management of electrical machines and drives (classical and unconventional), the more electric aircraft and electrified and hybrid propulsion. He is a Fellow of the Royal Aeronautical Society and a Senior Member of the IEEE. 